\title{
Punição da juventude e violência distópica: um desafio para professores na era do neoliberalismo globalizado
}

\author{
Punishing youth and dystopian violence: a challenge for teachers \\ in age of globalized neoliberalism
}

\author{
El castigo de jóvenes y la violencia distópica: un desafío para educadores \\ en la era de neoliberalismo globalizado
}

\begin{abstract}
\begin{tabular}{c} 
HENRY A. GIROUX* \\
\hline
\end{tabular}
RESUMO - Com a ascensão do fundamentalismo de mercado e o consequente colapso econômico e financeiro, a juventude de minorias pobres não são mais vistos como um investimento social, mas cada vez mais interpretados como um problema e um ônus social. Apanhados num poderoso complexo de controle de crime, a juventude é vista cada vez mais como mercadoria ou se vê submetida aos ditames de um sistema de justiça criminal em constante expansão. Ao ver seus protestos e reivindicações de educação de qualidade e a democracia radical como uma ameaça à ordem social, os jovens estão enfrentando crescentes níveis de violência de estado. $\mathrm{O}$ ataque à educação pública é um dos ataques mais perigosos lançados pelas forças da globalização e precisa ser desafiado pelos educadores públicos e a juventude.
\end{abstract}

Palavras-chave - Educação pública. Violência. Juventude. Esperança educada. Complexo de controle de crime.

\begin{abstract}
With the rise of market fundamentalism and the ensuing economic and financial meltdown, poor minority youth are no longer seen as a social investment but are increasingly interpreted as a social problem and burden. Caught in a powerful crime-control-complex, young people are either viewed increasingly as commodities or find themselves subject to the dictates of an ever-expanding criminal justice system. Viewing their protests and call for quality education and a radical democracy as a threat to the social order, young people are facing increasing levels of state violence. The assault on public education is one of the most dangerous attacks launched by the forces of globalization and needs to be challenged by all public educators and young people.
\end{abstract}

Keywords - Public education. Violence. Youth. Educated hope. Crime-control complex.

RESUMEN - Con el alzar del fundamentalismo de mercado y el consiguiente crisis económico y financiero, la minoría de jóvenes pobres no son más vistos como siendo un factor de inversión social, pero si son cada vez más interpretados como un problema social y un peso para la sociedad. Capturados dentro un poderoso complejo para el control del crimen, los jóvenes son mirados crecientemente como mercadería, o entonces encuentran a sí mismos sujetos a los preceptos de un sistema de justicia criminal en flanco crecimiento. Observando sus protestos y llamadas por educación de calidad, y la democracia radical como amenaza a la orden social, los jóvenes están enfrente a niveles crecientes de violencia por parte del estado. El ultraje a la educación pública es uno de los ataques más peligrosos puestos en marcha por las fuerzas de la globalización y que necesita ser desafiado por todos los educadores públicos, bien como por la gente joven.

Palabras clave - Educación pública. Violencia. Jóvenes. Esperanza educada. Complejo del control del crimen.

\footnotetext{
* Doutor em Educação pela Universidade Carnegie Mellon (Pittsburgh, PA, Estados Unidos da América) e Professor na Universidade MacMaster (Hamilton, Ontário, Canadá).E-mail: <henry.giroux@gmail.com>.
} 


\section{INTRODUÇÃO}

A juventude vive hoje numa era sem esperança, uma era em que é difícil sequer imaginar uma vida além do capitalismo de livre mercado ou superar o receio de que qualquer tentativa de fazê-lo só pode resultar no agravamento dessa situação. Nos Estados Unidos e em muitos outros países, a juventude se encontra numa conjuntura crítica dentro da história, definida por diversas crises que variam de uma economia que há muito tempo parcamente remunera o trabalho, o futuro de expectativas fracassadas, poucas perspectivas de mobilidade, taxas cada vez mais altas para a educação, e governos que atualmente mais punem a juventude do que investem em seu futuro. ${ }^{3}$ Mas, para a juventude, há muito mais do que pesadelos distópicos em relação ao futuro; há também uma esmagadora lista de evidências que revelam que a sociedade americana e muitas outras sociedades estão em guerra com suas crianças e jovens, e que o uso de tal violência contra a juventude é um indício perturbador de uma sociedade que se encontra no meio de uma profunda crise moral e política (CONWAY, 2010).

Além de expor a deterioração moral de uma nação que deixa de proteger sua juventude, a violência usada contra a juventude americana, em particular, refere-se a nada menos que um perverso desejo de morte, especialmente à luz do fato que Alain Badiou define como a era de tolerância zero para a juventude de minorias pobres e manifestantes juvenis, contrapondo-se à "infinita tolerância para crimes de banqueiros e fraudadores governamentais que afetam a vida de milhões" (2012, p. 18-19). Apesar da natureza sistêmica do ataque à juventude e seu testemunho à ascensão do livre mercado, e de que o estado da punição neoliberal tenha sido amplamente ignorado pela mídia atual, jovens do Chile, do Canadá, dos Estados Unidos e de diversos outros países estão resistindo à violência daquilo que se pode denominar um capitalismo de cassino (Cf. GIROUX, 2013; WOLFF; BARSAMIAN, 2012; HARDT; NEGRI, 2012; CHOMSKY, 2012). Por exemplo, o Ocupy Wall Street e o Quebec Protest Movements estão fazendo demonstrações contra tais ataques, ao mesmo tempo em que tentam educar o grande público sobre o quanto as esferas públicas, as instituições e os valores dos americanos e canadenses têm sido cooptados por uma cultura de violência grandiosa e impiedosa - amplamente dirigida contra manifestantes juvenis, marginalizados em razão de classe e raça, que têm se tornado cada vez mais alvos de implacáveis formas de punição sancionadas pelo estado.

Numa visão contextual e histórica, podemos ver que, no decorrer do tempo, as políticas de seguros coletivos e de proteção social, particularmente nos Estados Unidos, abriram caminho para as forças da privatização econômica, comoditização, desregulamentação e hiperindividualismo. Essas forças estão agora dirigindo o incessante ataque às esferas públicas democráticas, aos bens públicos e a toda noção viável de igualdade e justiça social. Nos últimos 35 anos, o público americano tem testemunhado o esvaziamento do estado de bem-estar por programas punitivos de benefícios trabalhistas, privatização de bens e espaços públicos e o malicioso apelo à responsabilidade individual e interesse pessoal, como um substituto para a responsabilidade cívica e o engajamento democrático (Cf. WOLFF, 2012; BELLAMY; McCHESNEY, 2012; MADRIK, 2010).

Abraçando a ideia de que valores e relações dirigidas pelo mercado devem moldar todo campo da vida humana, um modelo de governo empresarial desentranhou toda noção viável de valores públicos, ao mesmo tempo em que insidiosamente criminaliza problemas sociais e poda serviços sociais básicos, especialmente para a juventude, os pobres, as minorias, os imigrantes e os idosos (Cf. WACQUANT, 2009). Quando os jovens e outros grupos se organizam para protestar contra injustiça econômica e desigualdade massiva, drásticos cortes na educação, benefícios trabalhistas, pensões e serviços públicos, o estado tem respondido com o uso de violência ofensiva.

Em meio a tal violência, a mídia atual tem emitido insultos em vez de diálogo instrutivo, engajamento crítico e sugestões para uma reforma significativa. De fato, parece que os Estados Unidos entraram numa nova era histórica na qual decisões políticas se traduzem num desinvestimento intencional sistêmico em instituições públicas, acelerando ainda mais o colapso daquelas esferas públicas que tradicionalmente possibilitavam o provimento de condições mínimas de justiça social e expressão democrática. Étienne Balibar está certo em afirmar que no mundo todo estamos testemunhando o uso de violência pelo estado para minar o desenvolvimento das esferas públicas democráticas e o "uso sistemático de várias formas de violência extrema e insegurança em massa para impedir movimentos coletivos de emancipação que objetivem transformar a estrutura de dominação" (BALIBAR, 2004, p. 116-117).

$\mathrm{Na}$ frente doméstica, a violência do estado, em resposta ao movimento Ocupy, em seus primeiros seis meses foi decisiva e rápida: Houve pelo menos 7.719 detenções em mais de 112 diferentes cidades a partir de 12 de dezembro de $2012 .{ }^{4}$ De modo semelhante, em Montreal, no Canadá, milhares de manifestantes pacíficos foram detidos enquanto protestavam contra o aumento do custo da educação, o crescente ônus de dívidas e outros ataques aos jovens e à condição social. Que significa quando os jovens estão enfrentando cada vez mais formas de violência física, ideológica e estrutural porque estão articulando sua visão de um mundo íntegro e 
justo e reclamando a promessa de uma verdadeira democracia?

Abandonados pelos sistemas políticos existentes, os jovens estão se colocando em posição, ocupando espaços públicos acanhados num gesto simbólico, que toma inclusive medidas concretas, exigindo que sua presença seja reconhecida, quando suas vozes não mais são ouvidas. Em sua maioria, eles têm protestado pacificamente, enquanto tentam produzir uma nova linguagem, cultura política, instituições públicas e uma "comunidade que manifeste valores de equidade e respeito mútuo, que acreditam estar carecendo num mundo estruturado por princípios neoliberais" (BELLA, 2011). A juventude está se organizando em oposição à violência estrutural do estado enquanto tenta também recuperar o discurso do bem comum, da justiça social e da igualdade econômica. Rejeitando a ideia de que democracia e mercado são a mesma coisa, ou que capitalismo é o único sistema ideológico e econômico que pode falar em nome da democracia, os movimentos juvenis estão pedindo um fim à pobreza, ao estado de hostilidade dissidente e permanente e ao controle corporativo.

Muitos de nós fomos inspirados pela esperança do futuro melhor que esses jovens representam para a nação. Porém, é extremamente preocupante a reação enfrentada pelos manifestantes no exercício de seus direitos democráticos. Certamente, o que deve ser tratado por todos com interesse na salvaguarda do pouco que resta da democracia americana é a ameaça imediata da emergência de um estado policial que venha a embaraçar não somente os jovens manifestantes que ocupam algumas cidades norte-americanas, mas a promessa de uma verdadeira democracia. Essa ameaça à possibilidade de uma ordem social democrática apenas cresce com a ascendência de uma mentalidade bélica e métodos neoliberais de disciplina e educação, o que torna muito mais difícil sequer imaginar, quanto mais desempenhar obrigações públicas, responsabilidades sociais e engajamento cívico. A menos que as ações dos jovens manifestantes, por mais diversificadas que possam ser, sejam entendidas como uma forma de coragem cívica, comparável com uma democracia vital, será difícil ao público americano resistir ao aumento do estado de violência e ao enquadramento de protestos massivos e de dissidências pacíficas como antiamericanos ou, pior ainda, de uma espécie de comportamento criminoso.

Stuart Hall (2011b) sugere que o momento históricocultural, ou aquilo que ele chama a "longa marcha da revolução neoliberal", deve ser entendido em termos das diversas formas de violência que ela prepara e reforça. Tais pressões antidemocráticas e a provocação dos protestos dos jovens nos Estados Unidos e fora dele intensificaram uma crescente crise sintomática daquilo que Alex Honneth
(2009, p. 188) denominou a "socialidade fracassada" característica de estados neoliberais. Por sua vez, ideias alimentadas pelo estado e pela mídia corporativa a respeito de tal crise foram usadas para estimular temor e justificar a expansão rasteira de um estado militarizado e armado que reforça políticas neoliberais de crescente dissidência pública.

A violência da polícia contra a juventude deve, portanto, ser colocada dentro da mais ampla série de categorias que propiciam um entendimento crítico das forças sociais, econômicas e políticas subjacentes e que agem em tais ataques. Ou seja, para tratar adequadamente a violência patrocinada pelo estado contra a juventude, deve-se considerar o amplo contexto da degeneração do estado social e a correspondente ascensão do estado de hostilidade. Nos Estados Unidos, no Canadá e o no Reino Unido, a frequente violência em resposta a formas não violentas de protestos juvenis deve também ser analisada dentro da estrutura de um gigantesco estado militar-industrial, que acaba por estender a violência e a hostilidade para o interior de toda a sociedade.

\section{A PRODUÇÃO DA VIOLÊNCIA: MILITARIZAÇÃO COMO FORÇA MEDIADORA NA MOLDAGEM DE RELAÇÕES SOCIAIS}

Conforme a colocação do falecido filósofo Tony Judt (2009, p. 14-18), “Os Estados Unidos, em particular, estão se tornando não apenas um estado militarizado, mas uma sociedade militar: um país em que o poder armado é a medida de grandeza nacional, e a guerra, ou o planejamento da guerra, é o projeto exemplar comum (e único)". A metafísica da guerra e a violência relacionada influenciam cada vez mais todos os aspectos da vida cotidiana nos Estados Unidos, um processo que se intensificou desde 11 de setembro. A guerra e o militarismo não só consomem recursos e receitas públicas, mas determinam também o significado mais geral que molda os valores das relações sociais da vida cotidiana e são constituintes tanto do poder social como da própria cultura.

Sob o neoliberalismo, os mercados estão agora fundidos com a lógica bélica da militarização como modo de pensar, submetem posições, e o ordenamento das relações sociais, segundo observa o filósofo David Theo Goldberg (2011, p. 187), está fundido com a "verdade, a estrutura e a temporalidade militar". Certamente, o que quero dizer com isso é que os Estados Unidos estão não somente obcecados com os valores militares que moldam a política exterior, mas a guerra e o militarismo se tornaram uma força mediadora que ora se infiltra em quase todos os aspectos da vida cotidiana. A guerra faz homens e se torna a lógica mais importante que medeia não simplesmente a visão contemporânea de masculinidade, 
mas as relações sociais em geral. A guerra e sua dinâmica de crueldade e punição agora se infiltram em toda uma gama de instituições. Por exemplo, escolas e serviços sociais estão sendo cada vez mais modelados de acordo com as prisões, forças policiais sendo paramilitarizadas, e a cultura popular celebra perpetuamente o espetáculo da violência.

$\mathrm{O}$ assustador é que a lógica da guerra e da violência tornou-se um vício, se não algo perturbadoramente atrativo - uma necessidade socialmente construída da qual os americanos simplesmente não podem se afastar. A violência se tornou um princípio definidor e organizador da sociedade, uma das poucas forças mediadoras compartilhadas que agora mantêm coesa a vida cotidiana. O crucial aqui é reconhecer que "os campos da política e da violência - uma violência que parece carecer de organização racional, sem excetuar a autodestruição - não estão mais separados. Progressivamente, eles se tornaram reciprocamente permeados" (BALIBAR, 2004, p. 125).

A violência do estado está agora amplificada na ascensão do estado punitivo que funciona para apoiar os interesses corporativos e suprimir todas as formas de dissidência, visando tornar o poder corporativo justificável. A violência como um modo de disciplina é agora praticada em esferas que tradicionalmente foram criadas para se opor à violência simbólica e institucional perpetuada por formas de soberania de estado e corporativa. Aeroportos, escolas, serviços públicos e uma multidão de outras esferas públicas são agora definidas através de uma linguagem militarizada de disciplina, regulamentação, controle e ordem. O comportamento humano é agora reduzido à lógica utilitária da análise de custo-benefício, porção de mercado e porcentagem de lucro. As relações e o comportamento humanos não são simplesmente militarizados, vistos como alvos, mas são também materializados e desumanizados, tornando mais fácil legitimar uma cultura de crueldade e políticas de alienabilidade, que são princípios organizadores essenciais do cassino do capitalismo, questão à qual ainda retornarei.

A noção de conjuntura histórica - ou um conjunto paralelo de forças econômicas e militares que crescem em conjunto num dado momento - é importante ser analisada aqui, porque provê tanto uma abertura em fatores que moldam um momento histórico em particular, enquanto permite também a fusão da teoria e da estratégia em nosso entendimento das condições diante das quais nos encontramos. Nesse caso, ajuda-nos discutir teoricamente como os protestos jovens são amplamente relacionados a um projeto neoliberal historicamente específico, que promove imensas iniquidades em renda e riqueza, cria a dívida do empréstimo estudantil, elimina programas sociais altamente necessários, extirpa o salário social e privilegia lucros e mercadorias acima das pessoas.

A fusão do complexo militar-industrial com os interesses do estado e do desenfreado poder corporativo aponta para a necessidade de estratégias que tratem daquilo que é específico no projeto neoliberal atual e como os diferentes tipos de poder, relações sociais, pedagogias públicas e configurações econômicas se unem para moldar sua política. Tais considerações fornecem aberturas teóricas para tornar visível a prática do estado de hostilidade e a revolução neoliberal a fim de "colocar um fio cortante à resistência ao seu avanço, conteúdo e foco"(BELL, 1966, p. 706). Aponta também para o seu valor conceitual de deixar claro que a história continua a ser um horizonte aberto, que não pode ser descartado através de apelos ao fim da história ou ao fim da ideologia (BELL, 1966; FUKUYAMA, 2006). É precisamente através da natureza indeterminada da história que a esperança e a resistência se tornam possíveis.

No entanto, a esperança está em baixa entre os americanos de hoje, pois eles são dirigidos por temores comuns, alimentados em grande parte pela mídia-indutora de histeria. Corporações estão prontas para acentuar e reproduzir uma cultura de medo, com segurança e tecnologias de vigilância que, longe de prover maior segurança pública, pouco fazem além de garantir a contínua militarização de toda a sociedade, incluindo a mídia popular e os aparatos culturais que moldam a vida cotidiana. Imagens de tais abusos são abundantes na mídia atual. Há uma famosa imagem de uma mulher de 84 anos, olhando diretamente para a câmera depois de participar de um protesto, tendo a face encharcada com um líquido usado pela polícia.

Há a imagem de uma mulher grávida de 19 anos sendo levada para um lugar seguro, depois de levar spray de pimenta em intervenção policial. Agora existem imagens bem familiares de jovens puxados pelos cabelos na rua, sendo levados para um carro da polícia à espera (GOVREVITCH, 2011). Em alguns casos, os manifestantes foram seriamente feridos. Scott Olsen, um veterano da guerra do Iraque, foi severamente ferido num protesto em Oakland em outubro de 2011. Em 17 de março de 2012, jovens manifestantes que tentavam reocupar uma área no Zuccotti Park, em Nova Iorque, enfrentaram essa violência policial excessiva.

O jornal The Guardian noticiou que mais de 73 pessoas foram detidas em um dia e que "uma mulher foi capturada e algemada na calçada, outro manifestante foi jogado pela polícia contra uma porta de vidro antes de ser algemado, e uma jovem disse ter sido sufocada e puxada pelo cabelo... Testemunhas afirmaram que a polícia esmurrou diversas vezes um dos manifestantes na cabeça enquanto ele era dominado por pelo menos, 
quatro oficiais" (DEVEREUX, 2012). Histórias similares tornaram-se triviais nos últimos anos e são alarmantes lembranças da violência usada pelas forças de Jim Crow contra manifestantes de direitos civis, nos anos cinquenta e sessenta (ROCKSTROH, 2011).

Essas histórias são também indicadoras de que o difundido uso da violência e a celebração de valores belicosos não mais se restringem a uma ideologia militar em particular, mas normalizaram-se em toda a sociedade. Conforme Michael Geyer (1989) chamou à atenção, nesse sentido, a militarização é definida como "o processo social contraditório e tenso no qual a sociedade civil se organiza para a produção da violência". A guerra contra o terror tornou-se uma guerra contra a democracia, pois departamentos de polícia e policiais no país inteiro estão sendo supridos com os mais atualizados equipamentos e tecnologias militares importados diretamente dos campos de batalha do Iraque e do Afeganistão.

A obtenção de veículos aéreos não tripulados, caminhões blindados equipados com metralhadoras, veículos da SWAT e equipamentos digitais de comunicação como os usados pelos soldados em guerras externas" (GEYER, 1989, p. 79), é justificada pelas referências à guerra doméstica contra "terroristas" (código para jovens manifestantes). Ao mesmo tempo, o apelo à necessidade de combater terroristas domésticos provê novas oportunidades para os principais fornecedores e corporações de defesa se tornarem "cada vez mais parte integrante da nossa vida doméstica" (BECKER; SHULTZ, 2011). Conforme indica Glenn Greenwald (2011), desde 11/09, os Estados Unidos "paramilitarizaram agressivamente as forces policiais domésticas da nação, prodigalizando-as com incontáveis armas de uso militar e outras tecnologias semelhantes, treinando-as com táticas militares de guerra e em geral impondo-lhes uma mentalidade de guerra. Armar as forças policiais domésticas com armamentos paramilitares garantirá seu uso sistemático, mesmo na ausência de um ataque terrorista em solo Americano; simplesmente encontra-se algum outro uso permissivo para essas armas (BECKER; SCHULZ, 2011).

Com o crescimento de um novo estado militarizado, não será muito surpreendente que "aos 23 anos, quase um terço dos americanos seja detido por algum crime" (GREENWALD, 2011).Numa sociedade que não se preocupa ao ver minorias pobres e jovens de pouca renda como possíveis predadores - uma ameaça para o governo ou a população - sem dúvida, os violentos atos infligidos à juventude se multiplicarão com impunidade. As forças domésticas paramilitares certamente debilitarão a liberdade de expressão e se oporão à ameaça da força, ao mesmo tempo em que potencialmente violarão também as principais liberdades civis e direitos humanos.
Em outras palavras, o movimento predominante da sociedade americana rumo a um estado permanente de guerra monta o palco para a aceitação de um conjunto de símbolos de unificação, enraizado na sobrevivência da mais conveniente ética, que promove a conformidade acima da discórdia, o forte sobre o fraco e o temor sobre a responsabilidade civil. Com a emergência de uma sociedade militarizada, "a variedade de opiniões aceitáveis inevitavelmente encolhe" (GOODE, 2011), pois a violência se torna o primeiro e o mais importante elemento de poder e uma força mediadora na moldagem de todas as relações sociais.

A grave realidade é que a violência satura quase todo aspecto da cultura norte-americana. A violência promove Guerra contra o legado modernista de "questionar as premissas na filosofia, bem como na política e na arte" (JUDT, 2009, p. 17). A ignorância não é mais uma desvantagem em sociedades neoliberais, mas um recurso político continuamente mediado por um imaginário e uma sociedade capitalista que floresce nos índices interrelacionados de consumo, privatização e despolitização. A ignorância manufaturada é o novo modo reinante de violência distópica, estimulada por um sistema de mercado que celebra a paixão por bens de consumo acima de um desejo apaixonado por questões comunitárias, o bem-estar do outro e os princípios de uma sociedade democrática. Conforme argumenta Castoriadis (2010, p. 7) de forma brilhante, sob o neoliberalismo, a celebração imprudente do progresso econômico torna-se o princípio legitimador fundamental para transformar "seres humanos em máquinas de produzir e consumir".

Domesticamente, a violência, tal como uma corrente elétrica de alta voltagem, funde através da paisagem social e cultural tudo o que encontra em seu caminho. A cultura popular tornou-se uma base de criação para uma forma brutal de autoridade masculina, e a celebração da violência que incorpora tornou-se uma nova norma na América. As representações da violência dominam a mídia e muito frequentemente desfilam diante dos espectadores não como objetos de crítica, mas como um espetáculo em prol do lucro e elevada fonte de prazer. Tanto quanto qualquer forma de governo busca conformidade entre os governados, o estado permanente de guerra usa estratégias de pedagogia pública - práticas de persuasão pedagógica - para discursar, recrutar e formar sujeitos desejosos de se abrigar sob seus valores, ideologia e narrativas de temor e violência.

Nos Estados Unidos, a legitimação é grandemente alimentada por uma cultura dirigida pelo mercado viciada em consumismo, militarismo e espetáculos de violência organizada. Circulada através de vários registros da cultura popular, a crueldade e a violência imbuem os mundos da alta moda e os filmes de Hollywood, reality 
shows, esportes radicais, vídeo games, e a mídia só de notícias. O público americano é bombardeado por uma exposição sem precedentes a um "grande volume de... imagens de sofrimento humano" (CASTORIADIS, 2010, p. 8). Conforme argumenta Zygmunt Bauman (1995, p. 149),

a imensa quantidade e a monotonia das imagens podem ter um impacto desgastante [e], para evitar a "fadiga visual", elas devem ser cada vez mais sanguinárias, chocantes ou senão "inventivas" para suscitar qualquer sentimento ou de fato atrair a atenção. O nível da violência "familiar", abaixo do qual a crueldade de atos cruéis escapa da atenção, está em constante elevação.

\section{A CULTURA DA VIOLÊNCIA ESPETACULARIZADA: O ETHOS DO REFREAMENTO E DA PUNIÇÃO NAS ESFERAS DO COTIDIANO ESCOLAR}

Quando um grande volume de violência é injetado na cultura para alimentar esportes, entretenimento, mídia noticiosa e outros meios de busca de prazer, a violência altamente assustadora e aterradora de outrora perde o efeito de seu impacto. Uma das consequências é que as audiências de hoje apresentam mais do que uma mera dessensibilização ou indiferença à violência. Não são apenas consumidores passivos, mas, ao invés, demandam lascivas imagens de violência que alimentam sua crescente produção. A violência espetacularizada está desimpedida de considerações morais ou custos sociais.

Hoje ela (a violência) reside, se não medra, num diferente conjunto de aparatos culturais comercialmente infundidos que a oferta como uma mercadoria com o mais atraente e divertido quociente de prazer. Representações de tortura, assassinato, sadismo e sofrimento tornaramse material de puro entretenimento, oferecendo um degradante meio para experienciar intenso prazer e a emoção de um voyeurismo despolitizado e socialmente irresponsável. O sujeito consumidor é agora educado para ter intenso prazer em ver - se não também tomar parte em - espetáculos de crueldade e barbarismo. Afinal, assumir o papel de um primeiro atirador na era do barbarismo em videogame tornou-se um distintivo inquestionado tanto de prazer como de perícia, levando potencialmente a um emprego no Departamento de Defesa para operar a aeronave não tripulada no vídeo, covas saturadas de morto sem alguma cidade suburbana da costa oeste. Aparentemente desembaraçado de um limite moral baseado no respeito pela vida humana e não humana, a cultura dos Estados Unidos é cada vez mais formada por um perturbador desejo coletivo por excitamento intenso e um fluxo interminável de sensações intensificadas cada vez mais à disposição através de uma cultura de violência espetacularizada.

Embora não haja nenhum roteiro teórico para determinar com precisão como e por que a cultura coletiva continua a cair verticalmente, numa cultura espetacularizada, é bem mais fácil identificar a variedade das terríveis consequências e custos sociais provenientes desta imersão. Numa época em que as formas anteriormente incomuns de violência, tais como imagens extremas de tortura e morte, tornaram-se banalmente comuns, a violência que ocorre no dia a dia mal se tornou reconhecível - relegada ao domínio do não percebido e do imperceptível. A hiperviolência e representações espetaculares de crueldade interrompem e bloqueiam nossa capacidade de responder política e eticamente à violência enquanto ela está realmente acontecendo aqui. De que outro modo explicar a indiferença pública à violência promovida pelo estado contra jovens manifestantes não violentos que estão se rebelando contra uma sociedade na qual eles são excluídos de qualquer direito a esperança, prosperidade, igualdade e justiça? A crueldade saturou a vida cotidiana quando jovens, outrora objetos de compaixão e proteção social, são tratados de um lado como consumidores e mercadorias e, do outro, como suspeitos e criminosos.

A desconsideração para com os jovens e o crescente gosto pela violência podem também ser vistos em políticas que sancionam a configuração de escolas públicas à maneira de prisões, que tendem a punir a juventude desfavorecida, em vez de condenar as condições sociais que são forçados a suportar. Comportamentos anteriormente tratados por professores, conselheiros e administradores escolares são hoje tratados pela polícia e o sistema de justiça criminal. As consequências têm sido desastrosas para a juventude. As escolas não somente lançam mão de tecnologias e da cultura de prisões e se dedicam a punições humilhantes, crianças estão sendo detidas e julgadas por comportamentos que só podem ser chamados triviais. Houve, por exemplo o caso de uma menina de 5 anos na Flórida que foi algemada e colocada atrás das grades por ter um temperamento rebelde; ou a menina de 13 anos numa escola de Maryland que foi detida por se recusar a fazer o juramento de lealdade. Alexa Gonzales foi outra estudante detida pela polícia em Nova Iorque - por fazer rabiscos sobre sua mesa.

Há nesses casos muito mais que atos de excessiva estupidez e fuga de responsabilidade da parte dos educadores, dos pais, dos oficiais que impõem a lei e dos políticos que mantêm essas políticas. Há também o sentimento de que a juventude constitui uma ameaça aos adultos, e que a única maneira de tratá-los é submetêlos a castigos inconcebíveis. Estudantes que estão sendo deseducados, criminalizados e submetidos a formas de 
pedagogia penal em escolas tipo prisões, oferecendo um preocupante lembrete do quanto o ethos do refreamento e da punição se infiltra nas esferas do cotidiano, anteriormente eram amplamente imunes a esse tipo de violência oficial.

\section{Práticas de PUNiÇÃo COMO VIOLAÇÃO DA SUBJETIVIDADE E AUTORRECONHECIMENTO}

Um dos exemplos mais chocantes da tendência ao uso excessivo de formas de punição aos estudantes e de processá-los, chamado School-to Prison pipeline, está em plena exibição em dois relatórios recentes. Um deles, o relatório State Impact, afirmou que as escolas públicas da Flórida e de Ohio frequentemente usam uma prática disciplinar chamada "reclusão" (BAUMAN, 1995, p. 149-150). Isto é, repetidamente trancam "crianças em compartimentos tipo cela, banheiros ou velhos escritórios, algumas vezes sem o conhecimento de seus pais" (O'CONNOR; GONZALEZ, 2012a). Em Ohio, administradores escolares mandaram estudantes a salas de reclusão 4.236 vezes no ano letivo 2009-2010, sendo que sessenta por cento desses estudantes tinham “incapacidades" (O'CONNOR; GONZALEZ, 2012b).

Tais práticas assustam e não possuem qualquer valor educacional. Na verdade, descobriu-se que a "reclusão" é profundamente traumatizante para alguns estudantes, e em alguns casos as crianças tentaram se machucar ou cometer suicídio. O Think Progress relatou que "numa escola de educação especial em Geórgia, em novembro de 2004 um menino de 13 anos enforcou-se numa sala de reclusão" (SHEN, 2012). Nessa perspectiva, as coisas continuam piorando. O relatório de um Departamento de Justiça divulgou um School to Prison Pipeline em Mississipi, que revelou que o diretor e professores de escolas em Meridian, Mississipi, enviaram muitos estudantes negros com deficiência "à prisão por problemas de indisciplina [tais como] violação do código de vestimenta, vaidade, irreverência e desrespeito" (SHEN, 2012). Essas práticas disciplinares sugerem que estudantes pobres, com deficiência e vulneráveis se encontram em escolas que se tornaram "zonas de desamparo", e existem além das regras formais da administração escolar, nas quais os estudantes "tornaram-se irreconhecíveis, sem direito algum" (STRASSER, 2012). Em tais circunstâncias, os estudantes ficaram sem voz e, portanto impotentes, sujeitos a procedimentos disciplinares que apagam todo vestígio de função, subjetividade ou auto-reconhecimento.

Todas essas violações apontam para o contínuo e crescente fundamentalismo e "regra de exceções" no sistema político americano, que testemunha a crescente militarização da sociedade americana. Tais práticas disciplinares, apontam também para uma sociedade que não somente está em guerra com suas crianças e jovens, mas está também submissa a um galopante autoritarismo, no qual a principal função da educação é a repressão, especialmente para estudantes de baixa renda e pertencentes a minorias pobres, bem como aqueles com deficiências e necessidades especiais (BIEHL, 2005, p. 4). ${ }^{5}$ As escolas públicas para crianças de baixa renda e de minorias pobres transformaram-se naquilo que João Biehl denomina uma "maquinaria de morte social", onde a juventude considerada descartável é "frequentemente colocada em estado de "exclusão final" (ibid., p. 10-11, 14).

Políticas de governing-through-crime também nos lembram que vivemos numa era que arruína a juventude, corrompe a noção de justiça e satura cada minuto da vida cotidiana com a ameaça, se não com verdadeira violência. Um retorno a espetáculos violentos e outros tipos de punições medievais inflige dor, tanto à psique quanto ao corpo da juventude. Igualmente perturbador é como políticas e práticas de lei e ordem nos Estados Unidos parecem tomar o exemplo de uma antiga era de escravatura.

Estudos têm mostrado que "detenções e interações da polícia [...] afetam desproporcionalmente escolas de baixa renda, com elevadas populações afro-americanas e latinas" (SMARTYPANTS, 2010), preparando o caminho para que esses jovens facilmente passem por aquilo que foi chamado school-to-prison pipeline. Infelizmente, o próximo passo que se prevê para tal sociedade é um reality show da TV, sintonizado por milhões para ver garotos sendo algemados, detidos, julgados em tribunais e mandados para centros de detenção juvenil. Isso não é apenas barbarismo desfilando como corretivo - é também um ostensivo indicador do quanto o sadismo e a obsessão pela violência se tornaram uma norma numa sociedade que parece ter prazer em se desumanizar.

A violência tornou-se tão comum nos Estados Unidos que depois do terrível assassinato de 20 crianças estudantes e seis educadores da Sandy Hook Elementary em Newtown, CT, a poderosa National Rifle Association respondeu à tragédia com o pedido de que os professores da escola portassem armas. A mídia vigente realmente tratou isso como uma posição séria, apresentando essa opinião bizarra como uma séria alternativa à visão de que a regulamentação de armas deveria ser legalizada para ajudar a prevenir tais tragédias. Alguns estados aprovaram leis que permitem aos estudantes portarem armas escondidas nos campi universitários.

A predominância da violência institucionalizada na sociedade americana e de outras partes do mundo sugere a necessidade de uma nova conversação e política que mostrem como é um mundo justo e satisfatório. Enquanto educadores, intelectuais, acadêmicos, jovens 
e outros cidadãos interessados não discutirmos como a metafísica da guerra e da violência tomaram conta da sociedade americana e os bárbaros custos sociais que têm acarretado, fica impossível reconhecer e tratar as formas de violência social, política e econômica contra as quais a juventude vem protestando atualmente, bem como a violência promovida contra seus protestos.

O público americano precisa tornar visíveis e combater de forma decisiva as forças ideológicas, políticas, educacionais e econômicas subjacentes, que adotam a violência como mercadoria, espetáculo e modo de governar. Tal abordagem trataria da necessidade de entender a patologia emergente da violência, não apenas através de um discurso de medo ou manifestações isoladas, mas através de políticas que efetivamente implementem as mais amplas reformas sociais, econômicas e políticas necessárias para refrear a cultura de violência e as instituições sustentadas por ela.

Há um culto à violência na América, e ele é reforçado por um tipo de ignorância coletiva incessantemente difundida por forças especiais, tais como a National Rifle Association, políticos ligados a vantagens obtidas do complexo militar industrial e o complexo nacional corporativo de entretenimento que tanto emprega violência como a usa para reconfigurar o sentido das notícias, do entretenimento e das histórias que a América conta a si própria sobre sua identidade nacional e seu sense of destiny. Combater a violência de estado é mais que estender a ação do sistema jurídico criminal ao regime daqueles que ora dirigem os mais poderosos serviços e indústrias financeiras.

\section{A ESCOLA E SEUS PROFISSIONAIS COMO UM ESPAÇO DE RESISTÊNCIA A UM AUTORITARISMO PLANETÁRIO}

A violência deve também ser tratada dentro da pedagogia pública produzida pelo estado neoliberal de entretenimento. Isto é, deve ser tratada como parte da política da distração de uma pedagogia pública que despolitiza tanto quanto diverte os responsáveis pela corrupção. No âmago de tal análise, se encontra o foco altamente necessário sobre a emergência de novas formas de soberania corporativa, a mais intensa forma de violência intelectual, a implacável sobrevivência da ética mais adequada para legitimar o concentrado poder dos ricos e o esforço conjunto para punir jovens que estão em desacordo com a ideologia, os valores e o modo do governo neoliberal. O capitalismo globalizado é incompatível com a ideia de uma verdadeira democracia, e seu poder distópico se encontra, em parte, não somente no poder de sua maquinaria repressiva de força e violência, mas também na produção de aparatos culturais estreitamente controlados que produzem as culturas formativas nas quais indivíduos e públicos rendem seus desejos, subjetividades e identidades aos princípios rasos e violentos da ideologia neoliberal.

Certamente, essas tendências antidemocráticas representam mais que uma ameaça à juventude; elas colocam em perigo todos aqueles indivíduos, grupos, esferas públicas e instituições atualmente considerados disponíveis porque esses estão em desacordo com o mundo operado por banqueiros, a elite financeira e os ricos. A educação é particularmente vulnerável porque é vista como um mercado proveitoso para a elite financeira, assim como uma esfera pública que pode ser perigosa como esfera pública democrática.

Como um dos poucos lugares que ainda restam em que os estudantes podem aprender a pensar criticamente, empenhar-se em diálogo proveitoso e adquirir o conhecimento e as habilidades necessárias para serem cidadãos engajados, a escola oferece uma alternativa de resistência às tendências autoritárias que ora engolfam o planeta. Somente um movimento bem organizado de jovens, educadores, trabalhadores, pais, grupos religiosos e outros cidadãos interessados serão capazes de mudar as relações de poder e as enormes desigualdades econômicas que geraram aquilo que se tornou um país em que é quase impossível reconhecer os ideais de uma verdadeira democracia. Educadores jamais se importaram tanto em lutar pela democracia, e agora essa luta está entrando numa conjuntura histórica crucial.

Este desafio sugere o desenvolvimento de discursos e práticas pedagógicas que conectem a interpretação da palavra com a interpretação do mundo e que isso seja feito de modo a aprimorar as capacidades dos jovens como agentes críticos e cidadãos engajados. Ao assumir esse projeto, os educadores devem tentar criar as condições que deem ao estudante a oportunidade de se tornar crítico e cidadão engajado com o conhecimento e a coragem para se empenhar de modo a tornar a angústia e o cinismo inconvincentes, e a esperança, prática. Nesse caso, a esperança é educativa, diferente da fantasia do idealismo que é inconsciente das restrições que confrontam o sonho de uma sociedade democrática. Esperança educada não é um chamado para negligenciar as difíceis condições que moldam tanto as escolas como a ordem social mais ampla. É, ao contrário, a precondição para prover aquelas linguagens e valores que apontam o caminho de um mundo mais democrático e justo. Conforme argumentou Judith Butler, há mais esperança no mundo quando podemos questionar premissas do senso comum e acreditar que o que sabemos é diretamente relacionado à nossa habilidade de ajudar a mudar o mundo que nos cerca, embora esteja longe de ser a única condição necessária para tal mudança (apud OLSON, WORSHAM, 2000, p. 765). 
A esperança educada provê a base para se dignificar o trabalho dos professores; oferece conhecimento decisivo ligado à mudança social democrática, assevera responsabilidades compartilhadas e encoraja professores e estudantes a reconhecer a ambivalência e a incerteza como dimensões fundamentais da aprendizagem. Tal esperança oferece a possibilidade de pensar além do conhecido. Por difícil que essa tarefa possa parecer aos educadores, se não a um público mais amplo, é um esforço digno de se empreender.

Quero terminar insistindo que a democracia começa a falhar e a vida política se torna empobrecida na ausência daquelas esferas públicas vitais como a educação pública e superior na qual os valores cívicos, o conhecimento público e o engajamento social permitem uma percepção mais imaginativa do futuro que leva a sério as demandas de justiça, equidade e coragem cívica. A democracia deve ser um modo de pensar a educação - que prospera ao conectar equidade com excelência, aprendizagem com ética, e ação com as responsabilidades sociais imperativas e o bem público (DELBANCO, 2006). Talvez vivamos em tempos obscuros, mas o futuro ainda está em aberto. Já chegou o tempo de desenvolver uma linguagem política na qual os valores cívicos, a responsabilidade social e as instituições que os apoiam sejam essenciais para revigorar e fortalecer uma nova era de imaginação cívica, um renovado senso de ação social e uma vontade política fervorosa.

\section{REFERÊNCIAS}

ARONOWITZ, Stanley. Paulo Freire's pedagogy: not mainly a teaching method. In: LAKE, Robert; KRESS, Tricia. Paulo Freire's intellectual roots: toward historicity in praxis. New York: Continuum, 2012. (prelo)

BADIOU, Alain. The rebirth of history: times of riots and uprisings. Trad. Gregory Elliot. London: Verso, 2012.

BALIBAR, Ettienne. Outline of a topographie of cruelty: citizenship and civility in era global violence. We, the people of Europe? Reflections on transnational citizenship, Princeton: Princeton University Press, 2004.

BAUMAN, Zygmunt. Life in fragments. Malden: Blackwell, 1995. p. 149-150.

On education. Cambridge: Polity Press, 2012.

BECKER, Andrew; SCHULZ, G. W. Cops ready for war.2011 Dec. 21.Disponível em: <http://readersupportednews.org/newssection2/316-20/9023-focus-cops-ready-for-war>.

BELL, Daniel, The end of ideology: on the exhaustion of political ideas in the fifties. New York: Free Press, 1966.

BELLA, Kyle. Bodies in alliance: gender theorist Judith Butler on the occupy and Slutwalk Movements, Truth out, 15 Dec. 2011. Disponível em: <http://www.truth-out.org/bodiesalliance-gender-theorist-judith-butler-occupy-and-slutwalkmovements/1323880210>. Acesso em: 18 mar. 2012.
BELLAMY, John Foster; Mc CHESNEY, Robert W. The endless crisis: how monopoly finance capital produces stagnation and upheaval from the USA to China. New York: Montlhy Review Press, 2012.

BIEHL, João. Vita: life in a zone of social abandonment. Berkeley: University of California Press, 2005.

CASTORIADIS, Cornelius. A society adrift: interviews \& debates1974-1997. Tradução Helen Arnold. New York: Fordham University Press, 2010.

CHOMSKY, Noam. Occupy. New York: Zuccotti Park Press, 2012.

CONWAY, J. F. Quebec: Making war on our children. Socialist Project. E-Bulletin, n. 651.Disponível em: <http://www. socialistproject.ca/bullet/651.php>. Acesso em: 10 jun. 2012.

DELBANCO, Andrew. College: What it was, is, and should be. Princeton, NJ: Princeton University Press, 2006.

DEVEREAUX, Ryan. Dozens arrested as occupy Wall Street marks anniversary with fresh protests. The Guardian, 2012 Mar. 18. Disponível em: <http://www.guardian.co.uk/ world/2012/mar/18/occupy-wall-street-six-month-anniversary/ print $>$. Acesso em: 18 mar. 2012.

FUKUYAMA, Francis. The end of history and the last man. New York: Free Press, 2006.

GEYER, Michael. The militarization of Europe, 1914-1945. The Militarization of the Western World. Ed. John R. Gillis. New York: Rutgers University Press, 1989.

GOODE, Erica. Many in U.S. Are Arrested by Age 23, Study Finds. The New York Times, December 19, 2011. p. A15.

GIROUX, Henry A. Youth in a suspect society. New York: Palgrave, 2010a.

Smarty pants, "A failure of imagination," Smarty pants

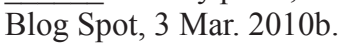

Youth in revolt. Boulder: Paradigm, 2013.

GOLDBERG, David Theo. Mission Accomplished: militarizing social logic. In: JEZIK, Enrique: Obstruct destroy. Conceal: Cuauhtemoc Medina; México: Universidad Nacional Autónoma de México, 2011. p. 187.

GOVREVITCH, Philip, Whose Police. The New Yorker. 2011. Disponível em: <http://www.newyorker.com/online/blogs/ comment/2011/11/occupy-wall-street-police-bloomberg.html> . Acesso em: 18 mar. 2011.

GREENWALD, Glenn. The roots of the UC-Davis PepperSpraying. 2011. Salon. Disponível em: <http://www. salon.com $/ 2011 / 11 / 20 /$ the_roots_of_the_uc_davis_pepper_ spraying $>$. Acesso em: 18 mar. $20 \overline{1} 1$.

HALL, Stuart. The neo-liberal revolution. Cultural Studies, 25: 6 Nov. 2011a, p. 706.

The March of neoliberals. The Guardian.2011b Mar. 12. Disponível em: <http://www.guardian.co.uk/politics/2011/ sep/12/march-of-the-neoliberals >. Acesso em: 12 dez. 2012.

HARDT, Michael; NEGRI, Antonio. Declaration. New York: Argo-Navis, 2012.

HONNETH, Alex. Pathologies of reason. New York: Columbia University Presss, 2009. 
JUDT, Tony. The New York Review of Books, v. 11, n. 12, p. 14-18, 2009 Jul. 14.

KRESS, Tricia. Paulo Freire's intellectual roots: toward historicity in praxis. New York: Continuum, 2012. (prelo)

MADRICK, Jeff. The age of greed. New York: Vintage Books, 2010.

O’CONNOR, John; GONZALEZ, Sarah. Many Florida schools use seclusion rooms for students with disabilities. State Impact: 2012a. Disponível em: <http://stateimpact.npr.org/ florida/2012/08/09/many-florida-schools-use-seclusion-roomsfor-students-with-disabilities/>. Acesso em: 18 mar. 2012.

OLSON, Gary; WORSHAM, Lynn. Changing the subject: Judith Butler's politics of radical resignification. J.A.C., v. 20, n. 4, 2000.

ROCKSTROH, Phil. The police state makes its move: retaining one's humanity in the face of tyranny. Common Dreams. 2011. Disponível em: <http://www.commondreams.org/ view/2011/11/15>. Acesso em: 18 mar. 2011.

SCHOR, Juliet, Plenitude. New York: The Penguin Press, 2010.

SHEN, Aviva. Ohio and Florida public schools lock mentally disaledchldren in closets. Think Progress, Aug. 9, 2012. Disponível em: <http://thinkprogress.org/ education/2012/08/09/667931/ohio-florida-school-closets>.

STANDING, Guy. The precariat: the new dangerous class. New York: Bloomsbury, 2011.

STRASSER, Annie-Rose. Mississippi schools sending kids to prison for misbehaving in the classroom, think progress. 2012. Disponível em: <http://thinkprogress.org/justice/2012/ 08/13/681261/mississippi-schools-sending-kids-to-prison-formisbehaving-in-the-classroom>. Acesso em: 13 ago. 2011.
TAYLOR, Danille. Conversations with Toni Morrison. Mississippi: Ed. Guthrie, University of Mississippi, 1994.

WACQUANT, Loic. Punishing the poor: the neoliberal government of social insecurity. Durham: Duke University Press, 2009.

WOLFF, Richard. Democracy at work: a cure for capitalism. Chicago: Haymarket Books, 2012.

WOLFF, Richard; BARSAMIAN, David. Occupy the economy: challenging capitalism. San Francisco: City Lights, 2012.

\section{Notas}

1 Referência ao romance Sulapublicado em 1974, um dos best-sellers (entre vários outros) da escritora Tony Morrison, que foi professora nas universidades de Yale e na Universidade Estadual de Nova York, em Albany e Princeton de 1970 a 1989. O romance traz a história de Sula e sua irmã, que desde crianças, enfrentaram o preconceito racial, e discorre sobre as formas de sobrevivência de crianças negras num mundo de preconceitos, opressão cultural, individual e social em bairros pobres dos Estados Unidos e de outros países.

2 TrechoeditadoporDanilleTaylor-Guthrie, do livroConversations with Toni Morrison, University Press of Mississippi, 1994, p. 103.

3 Aqui, eu me baseei amplamente em Zygmunt Bauman (2012). Para uma ampla análise da crise da juventude como classe precária, ver Giroux (2010) e Standing (2011).

4 Ver: <http://stpeteforpeace.org/occupyarrests.sources.html>.

5 Tomei esta ideia de escola como uma instituição repressora emprestada de Stanley Aronowitz (2012).

Artigo recebido em setembro 2013

Aprovado em novembro 2013. 